\title{
STRUCTURAL PERFORMANCE OF HYBRID MULTI- STOREY BUILDINGS WITH MASSIVE TIMBER-BASED FLOOR ELEMENTS LOADED UNDER EXTREME LATERAL LOADS
}

\author{
DANISH AHMED \& ANDI ASIZ \\ Department of Civil Engineering, Prince Mohammad Bin Fahd University, Saudi Arabia.
}

\begin{abstract}
Massive timber plate elements, specifically cross laminated timber (CLT), has gained popularity recently in North America as major alternative construction material for building components offering competitive advantages relative to traditional reinforced concrete slab for medium rise applications. There are two major structural applications for this kind of timber plate, as floor slab or shear wall components of multi-storey buildings. The following study will be focused on the structural performance of hybrid multi-storey buildings constructed using CLT plate as the floor slab elements. The specific objective of this paper is to investigate lateral deformability of floor diaphragm that is composed of CLT slab in combination with reinforced concrete and steel floor framing loaded under seismic excitation. Critical irregular floor layouts of medium rise buildings are selected and modeled using computer structural and building analysis software ETABS. Major outputs including lateral floor deformation (drift), storey shear and dynamic characteristic analyses are analyzed and contrasted with the current design practices, i.e. building code application with respect to diaphragm assumption for seismic design. As in the reinforced concrete-based floor diaphragm, expected general outcome from this study is to provide input for design code provision regarding whether rigid, flexible, or in-between (semi-rigid) assumption of CLT-based diaphragm is adequate for performing design standard procedure for seismic design of hybrid multi-storey buildings. Structural analysis and modeling challenges for CLT-based diaphragm used in hybrid multi-storey buildings are presented and design recommendations will be given.

Keywords: cross laminated timber, diaphragm rigidity, hybrid timber building, lateral load design.
\end{abstract}

\section{INTRODUCTION}

Massive timber plate such as cross laminated timber (CLT) has been very popular recently in North America as alternative major structural components in multi-storey building applications. Traditionally in North America, timber has been used mainly for low-rise buildings with light-frame construction system. CLT has changed the perspective of people in the building construction sector due to its comparable strength and serviceability performances relative to reinforced concrete slabs. Additional general benefits of timber-based material in building construction include: encouraging prefabrication leading to fast and in-expensive construction practice, promoting energy efficient building due to low thermal conductivity of wood and environmentally friendly material assisting in reducing carbon emission [1]. There has been several heavy timber buildings involving CLT plate have been or already been constructed in Canada and US as well as in other part of the world such as Australia. CLT was developed in Europe in the early 90s and it has been used extensively since then for housing and commercial building applications. Building code and regulation in Europe has been well developed and been supported by strong research and development from various commercial and academic timber-based institutions. North American timber community has followed the same path as the European partners to establish common design practices with necessary adjustment in the regulation due to different challenge with respect to the environmental factors. 
There have been many research studies about utilizing CLT potential for hybrid multi-storey buildings. Hybrid here means that CLT can be used in combination with steel or reinforced concrete floor framing including lateral load resisting systems such as steel moment frame or reinforced concrete shear wall. From some of the research outcomes by Asiz and Smith [2-4], it has been shown that CLT slab as floor component is not only feasible for tall buildings with steel or reinforced concrete frameworks under extreme earthquake load, but it is also very competitive relative to reinforced concrete slab due to smaller drifts generated and low demand on the foundation loads. However, there are few challenges that need to be addressed in order to make CLT virtually unlimited use in tall building applications. The first challenge is in-plane deformability of the CLT-based diaphragm considering its stiffness different with that of the lateral load resisting system. Another challenge is ensuring continuity of floor diaphragm with CLT that is formed through few plates (due to limited span capability) connected through several in-between-plate joints including perimeter-joints with steel or concrete girder floor framing. Major challenge is that can we treat CLT-based floor diaphragm as homogenous or monolith material as in the reinforced concrete without ignoring its directional properties. What level of confident is needed to achieve this assumption, i.e. what needs to be accounted in the code design provisions? Furthermore, what level of modeling can be implemented to analyze hybrid buildings with CLT as slab component in the diaphragm, i.e. do we need to model everything from plate down to individual connections; or what level of confident needs to be incorporated. This question becomes so apparent when it comes to analyzing tall building with complex or irregular floor layouts combined with advanced lateral load resisting systems.

Floor diaphragm is one of the critical components in multi-storey buildings. It has major roles resisting gravity load and transferring external loads to the building lateral load resisting system such as moment frame connection or shear wall. Diaphragm must be designed with sufficient out and in-plane stiffness and strength along with adequate connection system to that lateral load resisting system. In the current design practices, floor diaphragms of multi-storey building subjected to lateral load may be modeled as fully rigid without in-plane deformability. Even though this practice is relatively accepted as a reasonable approach for several steel and reinforced concrete buildings, certain floor and building configurations may exhibit significant in-plane diaphragm flexibility. One of the interesting research outcomes that timber-based community can learn is that the rigid-floor assumption can lead to significant errors in term of lateral load distribution if the building has reinforced concrete shear wall that has big stiffness differences with that of floor diaphragm [5]. Studies conducted by Saffarini and Qudaimat [6] and Moeni and Rafezi [7] demonstrated that several notable building codes have in disagreement classifying diaphragms as flexible or rigid when it comes to irregular building with shear walls. If the reinforced concrete diaphragm has still debatable issues on its flexibility assumption, it is certainly expected that timber-based diaphragms have similar design challenges. It is the main intention of this study to investigate the CLT-based diaphragm deformability.

Two major types of building were examined in this study, reinforced concrete and steel framework both with concrete and CLT slabs for the floor diaphragms. In the reinforced concrete skeleton, medium rise buildings with selected irregular floor layouts were used in the analysis. Medium seismic intensity was applied. In the steel skeleton, a medium rise building with moment (rigid) connections and a tall (slender) building with reinforced concrete shear walls loaded under heavy seismic load were analyzed. The results were compared using reinforced concrete slab as reference with the focus on contrasting between rigid and flexible 
modeling assumption of the floor diaphragm. It is anticipated that the research outcomes will provide basis for design and modeling guidelines for equivalent static lateral load method used in analysing multi-storey buildings with timber-based floor diaphragms.

\section{BUILDINGS WITH REINFORCED CONCRETE FRAME WORK}

\subsection{Modeling}

Three low-rise reinforced concrete frames with different floor layouts (rectangular, L, and U shapes) were studied (Fig. 1). The rectangular floor layout has relatively long and narrow shape to capture extreme flexibility level and storey load-shear distributions generated under seismic load. The $\mathrm{L}$ and $\mathrm{U}$ shapes were analyzed to show how the diaphragms will response when simple irregular floor shapes are imposed. Narrow shear walls and rectangular columns were used as the main lateral load resisting (vertical) systems, and the intention here is to demonstrate how flexible the diaphragms will response when the stiffness differences between the vertical and horizontal (diaphragm) elements are significant. Detail dimensions of the columns and shear wall can be seen in Table 1. Two slab materials were used for the floor framing, concrete with the average thickness of $150 \mathrm{~mm}$ and CLT slab with average thickness of $250 \mathrm{~mm}$ (7-layer ply). Table 2 shows the details of mechanical properties of concrete and CLT. The CLT-based floor is composed of many CLT panels connected to the reinforced concrete frames with long screws having adequate stiffness and spaced such that ensuring adequate force transfer between the CLT slab and concrete floor framing [3]. The interconnected CLT panels are also connected using screws to ensure adequate internal force transfer between panels.

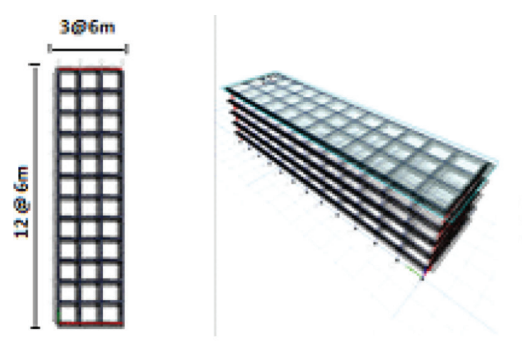

(a) Rectangular-shape

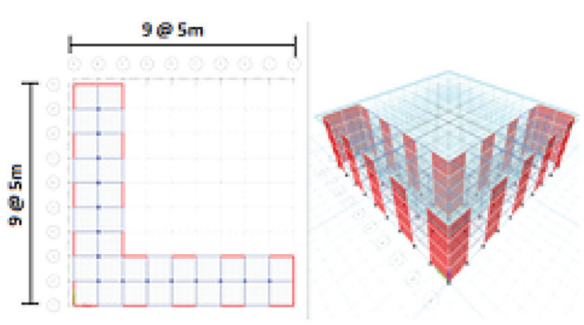

(b) L-shape

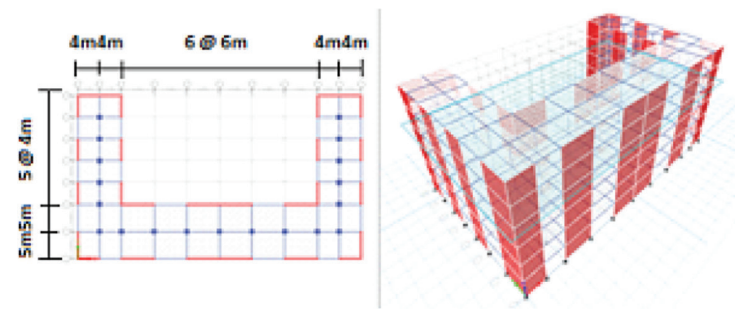

(c) U-shape

Figure 1: Floor layouts and 3D view of the buildings. 
Table 1: Dimensions of the building frames.

\begin{tabular}{lllllll}
\hline $\begin{array}{l}\text { Shape of } \\
\text { Buildings }\end{array}$ & $\begin{array}{l}\text { Beam } \\
\text { section } \\
(\mathrm{cm})\end{array}$ & $\begin{array}{l}\text { Column } \\
\text { section }(\mathrm{cm})\end{array}$ & $\begin{array}{l}\text { Slab thickness } \\
(\mathrm{cm})\end{array}$ & $\begin{array}{l}\text { Shear wall } \\
\text { thickness } \\
(\mathrm{cm})\end{array}$ & $\begin{array}{l}\text { Number of } \\
\text { stories }\end{array}$ & $\begin{array}{l}\text { Story } \\
\text { height } \\
(\mathrm{m})\end{array}$ \\
\hline Rectangular & $50 \times 80$ & $80 \times 80$ & 15 & 15 & 5 & 4 \\
L shape & $40 \times 80$ & $50 \times 50$ & 12 & 15 & 4 & 4 \\
U shape & $50 \times 80$ & $80 \times 80$ & 15 & 30 & 6 & 4 \\
\hline
\end{tabular}

Table 2: Mechanical properties of CLT slab.

\begin{tabular}{lll}
\hline & Concrete & CLT \\
\hline Directional property & Isotropic & Orthotropic \\
Density $(\mathrm{kg} / \mathrm{m} 3)$ & 2400 & 400 \\
Elastic modulus $(\mathrm{GPa})$ & 25 & $\mathrm{E}_{1}=9, \mathrm{E}_{2}=4.5, \mathrm{G}_{12}=0.5$ \\
Poisson's ratio & 0.25 & $\mathrm{v}_{12}=0.3$ \\
Strength $(\mathrm{MPa})$ & 27.5 & $\mathrm{f}_{\mathrm{t}-1}=20, \mathrm{f}_{\mathrm{t}-2}=15, \mathrm{f}_{\mathrm{c}-1}=30, \mathrm{f}_{\mathrm{c}-2}=25, \mathrm{f}_{\text {shear }}=5$ \\
Notation: $\mathrm{E}=$ modulus of & & \\
elasticity; $\mathrm{G}=$ modulus of & & \\
rigidity; 1 = CLT major & & \\
direction; 2 = CLT minor & & \\
direction; $\mathrm{t}=$ tension; & & \\
$\mathrm{c}=$ compression &
\end{tabular}

Fully 3D finite element models using ETABS [8] was used to predict structural responses of these buildings subjected to seismic load. Concrete and CLT slabs were modeled as fournode shell elements having six degree of freedoms, three translations and three rotations. For the flexible diaphragm case, the floor shell elements were modeled using the actual mechanical properties given in Table 2. For the rigid assumption, infinite lateral stiffness was assigned to the shell elements including the connector's stiffness for the case of CLT floor to ensure that each floor level move together laterally with the same drift value. The meshing of the shell-floor elements were created such that it can at least facilitate placement of the spring connector's element. There is another way in modern computer structural analysis to directly model diaphragm as rigid by creating what so called master degree of freedom at the center of floor mass. All other nodes at the respected floor are tied to the master node and moved together laterally. The equivalent static lateral load is normally distributed in the master degree of freedom having two in-plane translations and one in plane-rotation. This method considerably saves computer resources and time used due to significant reduction in the number of degree of freedoms. However, using the equivalent static lateral analysis is proven to be challenging due to presumption about flexible and rigid diaphragms.

The connections between concrete slab and the reinforced concrete building frames were made rigid to ensure composite action; whereas for the CLT slab, connections were modeled as rigid spring or spring elements with assigned stiffness derived from available long-screw test data (e.g. Ref. [3]) and spaced at $200 \mathrm{~mm}$. All building frames were modeled as fix to 
ensure extreme structural responses under lateral loads. Linear dynamic analysis with response spectrum method was used to apply seismic load (with peak ground acceleration $0.3 \mathrm{~g}$ ) at the building base without making presumption about lateral load distribution to the diaphragms such is done in the equivalent static lateral load. This seismic load level can be associated to the mid regions of North American continent, or the Mid-East GCC countries, which recently requiring all multi-storey buildings be designed with respect to moderate seismic load. However, the study outcomes can be extrapolated to other heavy seismic regions as long as the analysis is performed within the linear dynamic and elastic limits. Cautions must be taken in the modeling and analysis when geometric non-linearity is applied along with inelastic response of the timber-to-frame connections.

\subsection{Results}

Figures $2-4$ show the analysis results for the story drifts under combination of seismic and dead loads with flexible and rigid diaphragm models incorporated both for concrete and CLT slabs. In general, it can be seen that all CLT-based floors resulted in less drifts relative to the concrete slab with the same modeling assumption. The results have been consistent with those of previous studies conducted by Asiz and Smith [2-4] confirming the lightness nature of CLT material compared to concrete. However, this study is not intended for comparing CLT versus concrete, but investigating how far CLT-based floor diaphragm can be assumed rigid, learning from concrete diaphragm responses. Even though it is not discussed in detail in this study, the CLT-based floor satisfied the requirement under gravitational (dead) load considering the same span as in the concrete. Also, the principle stresses developed were

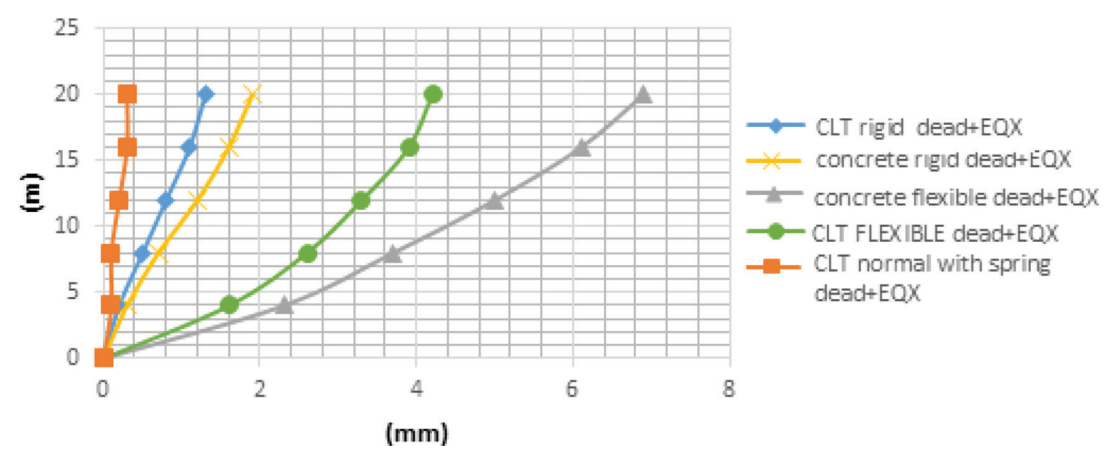

Figure 2: Storey drifts for the narrow rectangular shape.

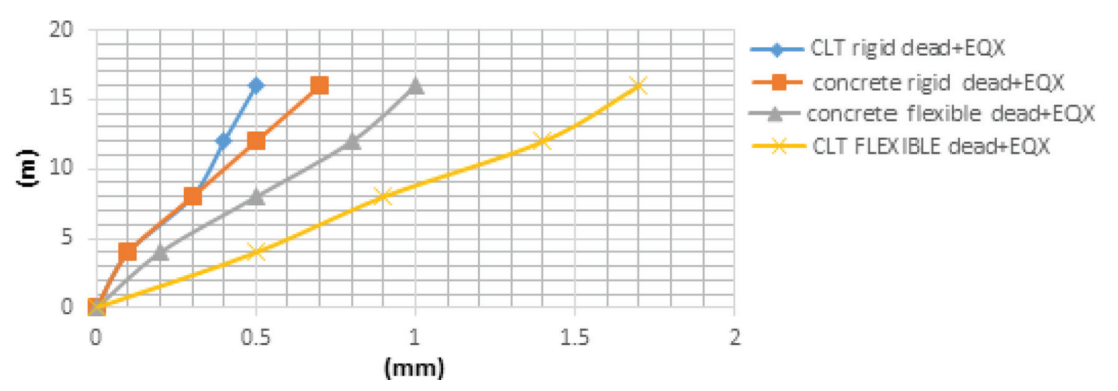

Figure 3: Storey drifts for the L shape. 


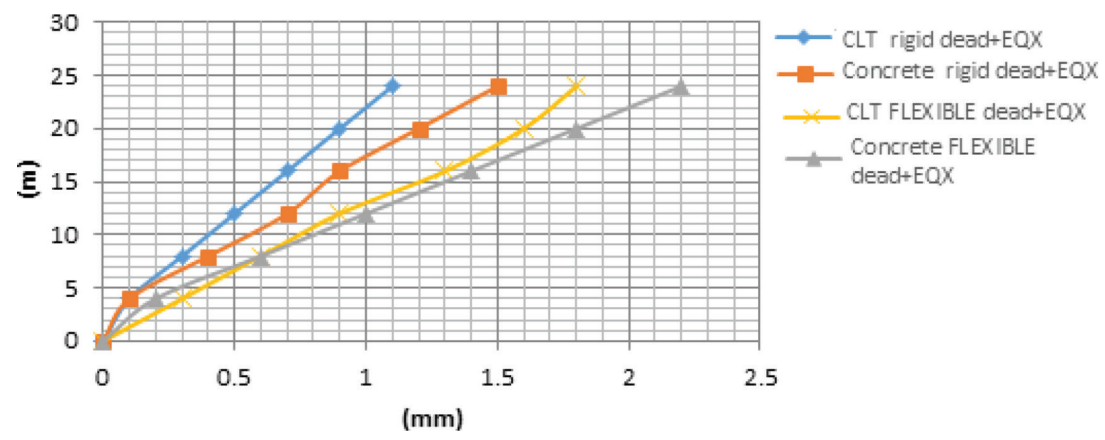

Figure 4: Storey drifts for the U shape.

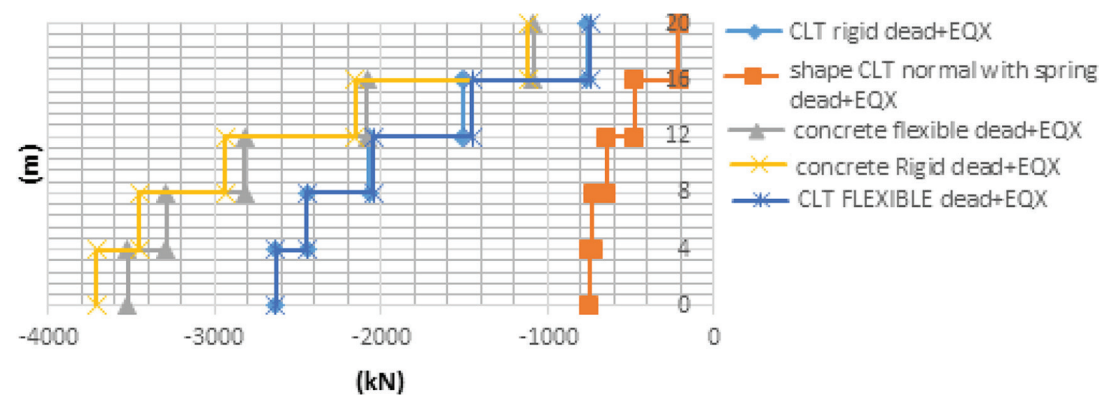

Figure 5: Storey shear for rectangular floor shape.

compared with the failure criterion applicable in wood and the results indicate that strength requirements were fulfilled.

Figure 2 shows the CLT slab performance under three different modeling assumptions: rigid, flexible with rigid connection between the slab and floor frames, and flexible with assigned (spring) stiffness in the connection between the slab and floor frames. For the case of concrete slab, only two modeling assumptions were applied, rigid and flexible both with rigid connection to ensure fully composite action. As was seen in Figure 2, the CLT with the actual (spring) connections produces the smallest drift due to some slips generated dissipating energy from the lateral seismic load. The maximum drift difference between rigid and flexible floor diaphragms in the CLT slab is around 69\%, and for the concrete slab is slightly higher around $72 \%$. Surprisingly, the rigid assumption for the CLT floor slab resulted in closer drifts compared with those of the flexible model with assigned spring stiffness. For the L shape, the maximum drifts generated between the CLT flexible and rigid diaphragms resulted in $71 \%$ difference, whereas for those of concrete slab only $30 \%$. For the U shape, the CLT slab produces $39 \%$ different in the modeling assumption between rigid and flexible, while for those of concrete slab was $32 \%$. In general it can be deduced that the difference in the maximum drift responses between rigid versus flexible are significant.

Figures 5-7 show the shear storey distributions for all floor shapes. Unlike the drift, in general, the agreement between rigid and flexible modeling assumptions was close both for the CLT and concrete slabs. However, significant difference was obtained between modeling connections as rigid versus flexible for the CLT slab. It can be deduced from here that neglecting the flexibility factor for diaphragms lead to erroneous results for the shear storey distributions. 


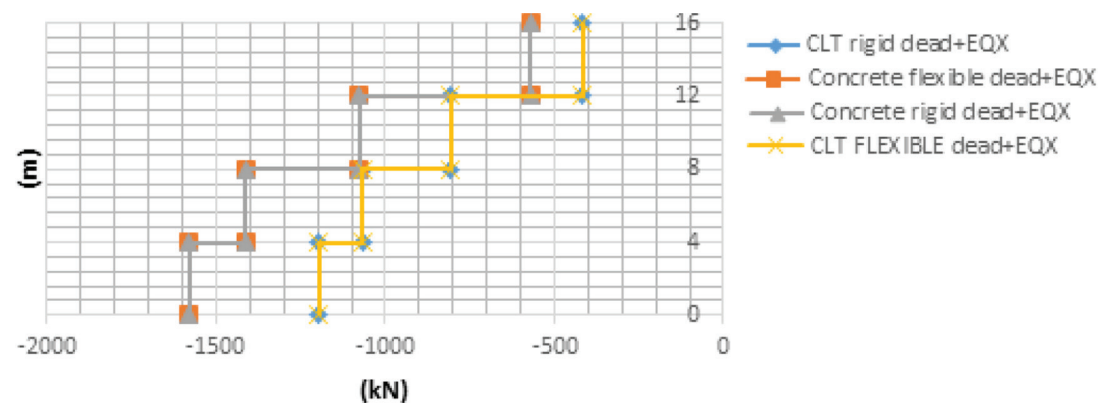

Figure 6: Storey shear for L floor shape.

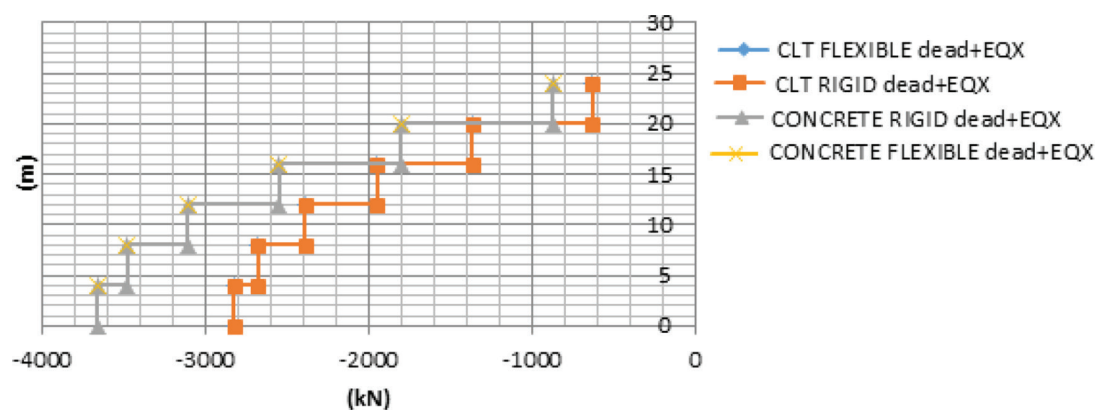

Figure 7: Storey shear for U floor shape.

Table 3: Fundamental period and frequency comparisons.

\begin{tabular}{|c|c|c|c|c|c|c|c|c|c|c|c|c|c|}
\hline & \multicolumn{5}{|c|}{ Rectangular shape } & \multicolumn{4}{|c|}{ L shape } & \multicolumn{4}{|c|}{ U shape } \\
\hline & \multicolumn{2}{|c|}{ Concrete } & \multicolumn{3}{|l|}{ CLT } & \multicolumn{2}{|c|}{ Concrete } & \multicolumn{2}{|l|}{ CLT } & \multicolumn{2}{|c|}{ Concrete } & \multicolumn{2}{|l|}{ CLT } \\
\hline & $\mathrm{R}$ & $\mathrm{F}$ & $\mathrm{R}$ & $\mathrm{F}$ & $S$ & $\mathrm{R}$ & $\mathrm{F}$ & $\mathrm{R}$ & $\mathrm{F}$ & $\mathrm{R}$ & $\mathrm{F}$ & $\mathrm{R}$ & $\mathrm{F}$ \\
\hline $\begin{array}{l}\mathrm{T} \\
(\mathrm{s})\end{array}$ & 0.64 & 0.64 & 0.54 & 0.54 & 0.17 & 0.17 & 0.19 & 0.15 & 0.23 & 0.28 & 0.39 & 0.24 & 0.36 \\
\hline $\begin{array}{l}\text { Freq. } \\
(\mathrm{Hz})\end{array}$ & 1.56 & 1.56 & 1.86 & 1.86 & 5.83 & 5.87 & 5.29 & 6.82 & 4.32 & 3.56 & 2.56 & 4.19 & 2.81 \\
\hline
\end{tabular}

$\mathrm{R}=$ rigid, $\mathrm{F}=$ flexible, $\mathrm{S}=$ spring

Table 3 presents the fundamental period and natural frequency of the building studied. It is important to know the fundamental period of a building, because it is used to determine the equivalent static lateral load distribution based on rigid-design assumption of the diaphragm. It should be noted that several code provisions suggested that most of the fundamental period of a building depends heavily on the total building height. It can be seen that the difference between rigid and flexible modeling assumption is not significant for rectangular shape, and the difference becomes wider for the $\mathrm{L}$ and $\mathrm{U}$ shapes specifically for CLT slab. This is one of 
the indications that CLT slabs behave more flexible relative to concrete slabs. Cautions must be taken when designing storey shear distribution using the static equivalent method.

\section{BUILDINGS WITH STEEL FRAME WORK}

\subsection{Modeling}

6- and 24-storey steel frame buildings were modeled (Fig. 8). Typical floor layout for the six-storey building is $19.2 \mathrm{~m} \times 12.8 \mathrm{~m}$, and for the 24-storey is $38.4 \mathrm{~m} \times 25.6 \mathrm{~m}$. As was in the reinforced concrete framework, two major models were incorporated in the floor diaphragm models utilizing concrete and CLT slabs: rigid and flexible. For the six-storey building, which will be representing low-rise building with simple floor layout, the lateral load resisting system was carried by moment connection in the steel frame. For the 24-storey case representing tall building with complex floor layout, the lateral load resisting systems consisted of RC shear wall cores in combination with moment resisting frame (RC or steel framework). Major load considered was wind and earthquake with the intention to obtain what load governs for this type of building configurations. Loads combinations considered included effects of gravity (self-weight and imposed floor and roof loads), seismic load with peak design acceleration $0.5 \mathrm{~g}$, and wind forces with basic wind speed $240 \mathrm{~km} / \mathrm{h}$. Details of the loads data and load combination factors are given in Asiz and Smith [2]. These extreme loads combination would actually never be done in the design practice. Nevertheless, it is important design information considering hypothetically building located in the extreme zone with respect to earthquake or wind load. As was in the reinforced concrete frame, the floor and roof components were modeled as four node shell elements. Linear dynamic analysis via response spectrum method was used to apply seismic load. The material properties used in the flexible floor analysis both for concrete and CLT slabs are given in Table 1. Modulus of elasticity for the steel is $200 \mathrm{GPa}$ with Poisson's ratio of 0.3 and strength of $250 \mathrm{MPa}$. The steel frames shown in Figure 8 were sized based on AISC [9].
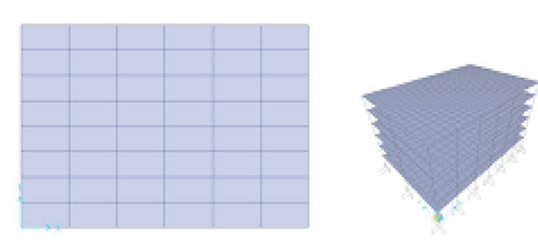

\begin{tabular}{|c|c|}
\hline \multirow[t]{2}{*}{ Columns } & $1^{\text {st }}-3^{\text {rd }}: W 14 \times 90$ \\
\hline & $4^{\text {th }}-6^{\text {th }}:$ W $176 \times 90$ \\
\hline Main beams & W $24 \times 94$ \\
\hline Secondary beams & W $16 \times 49$ \\
\hline
\end{tabular}

(a) 6-storey building with 4 -m-height at each level with steel frames used

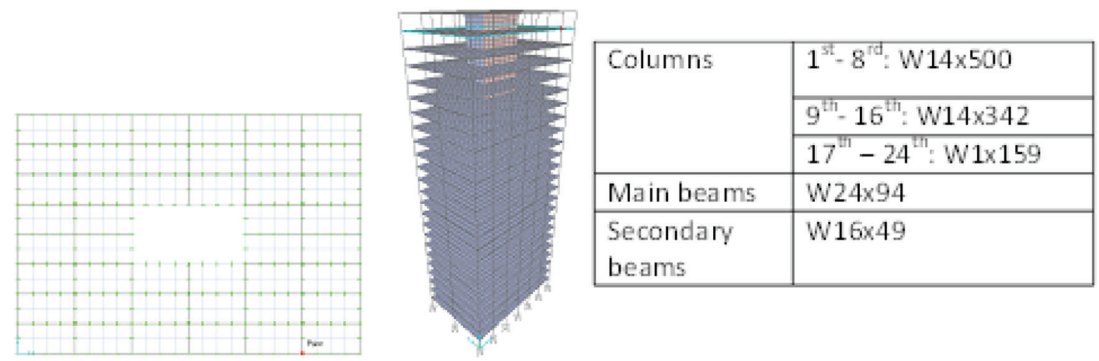

(b) 24-storey building with 4-m-height for each level with the steel frame used

Figure 8: Floor layouts and 3D view of the buildings studied. 

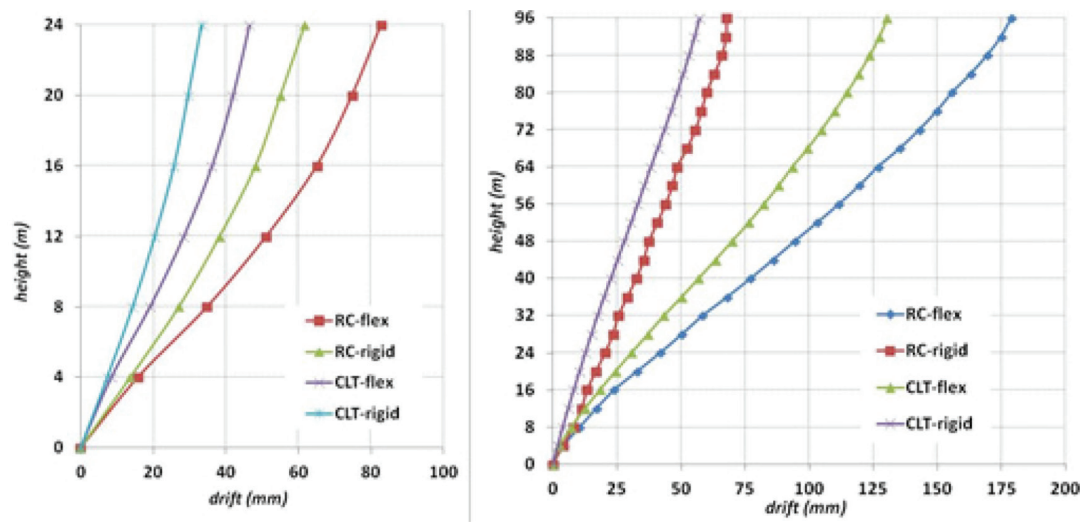

Figure 9: Drift analyses.

Table 4: Fundamental period (seconds).

\begin{tabular}{lllll}
\hline & 6-storey & \multicolumn{3}{c}{ 24-storey } \\
\cline { 2 - 5 } & RC & CLT & RC & CLT \\
\hline Flexible & 1.23 & 0.73 & 2.91 & 1.98 \\
Rigid & 0.97 & 0.52 & 1.41 & 0.74 \\
\hline
\end{tabular}

Table 5: Maximum base shear $(\mathrm{kN})$.

\begin{tabular}{lllll}
\hline & 6-storey & \multicolumn{3}{c}{ 24-storey } \\
\cline { 2 - 5 } & RC & CLT & RC & CLT \\
\hline Flexible & 3,558 & 2,082 & 10,276 & 7,129 \\
Rigid & 4,031 & 2,521 & 17,461 & 14,602 \\
\hline
\end{tabular}

\subsection{Results}

It was found from the analysis that the seismic and dead load combination govern the critical load for these two buildings. Figure 9 shows the drifts for both 6- and 24-storey buildings using concrete and CLT slabs. The drifts obtained in this study were less than the allowable drift stated in the building codes (e.g. Refs. $[10,11])$. As was the reinforced concrete framework, CLT floor system has much lower drift relative to concrete slab. Again, this is a direct reflection of the mass of the CLT slabs being only about half of the mass of equivalent concrete slabs.

For the flexibility analysis, ratio of the drift between flexible and rigid floors was compared. For the six-storey case, the ratio found in CLT system was 1.15 (first storey) to 1.39 (sixth storey) where the latter value indicates the highest storey ratio. As expected, the ratio is getting bigger when the storey gets higher. While the ratio in concrete slab is 1.15 to 1.34 
slightly lower than that of CLT's. For the 24-storey case, the ratio in CLT slab is 1.37 to 2.28, and in RC system 1.07 to 2.65 . Regardless of the floor materials used, the ratio in the 24th level is highest indicating that the error obtained is biggest. This is because in the 24-storey case, the floor layout is much more complex compared to the 6-storey layout. Also, this indicates that the vertical stiffness of the lateral load resisting system that is carried by the RC shear wall is much higher than the horizontal stiffness of the floor system. By comparing the flexibility of the floor material used, as anticipated, concrete slab diaphragm showed higher lateral stiffness particularly for the 24-storey case.

Trends were also observed when analogous ratios are applied to the fundamental structural period and maximum base shear, as shown in Tables 4 and 5 below. Based on the case study results, it can be concluded that it is necessary to model floor as flexible regardless of the floor materials used particularly for the case of irregular floor layout, i.e. floor that has lower horizontal stiffness compared to the lateral stiffness of the lateral load resisting system.

\section{DISCUSSION}

It can be concluded from the buildings examined here that for the reinforced concrete frames, the vertical stiffness of the lateral load resisting systems overpower the lateral stiffness of the diaphragms regardless the materials used for the slab. This was indicated by big margin of errors obtained between rigid and flexible drift responses. The comparative error in the modeling assumption between rigid versus flexible is a little higher for the case of CLT slab. In the case of the steel frame buildings, the diaphragm response for both concrete and CLT slabs can be considered to be rigid, with CLT slabs generates slightly stiffer diaphragms. It should be noted here that the flexible terminology is related to modeling assumptions and not to be confused with design assumptions, since the outcomes of this modeling exercise will be used as guidance whether design assumption (rigid versus flexible diaphragm) is adequate to obtain the distribution of seismic demand to the lateral load (vertical) resisting elements. There needs to be design guidance to determine the lateral stiffness ratio between diaphragms and lateral load resisting system, particularly for timber-based floor elements. The practice used in concrete can be adopted with slight adjustment for timber-based floor diaphragm.

Seismic design code provisions (e.g. Ref. [12]) generally accept rigid assumption for diaphragms for the purpose of distributing storey shear to the lateral load resisting elements provided that the lateral deformation of the diaphragm is less than or equal to two times the average storey drift (Fig. 10). Using the defined flexibility ratio shown as shown in Figure 10, diaphragms response can be numerically assessed. For example, the deformed shape of the critical diaphragm of the 24-storey building with the steel framework system indicates that CLT slab has flexibility ratio around 2.5 and the concrete slab has a slightly lower value of

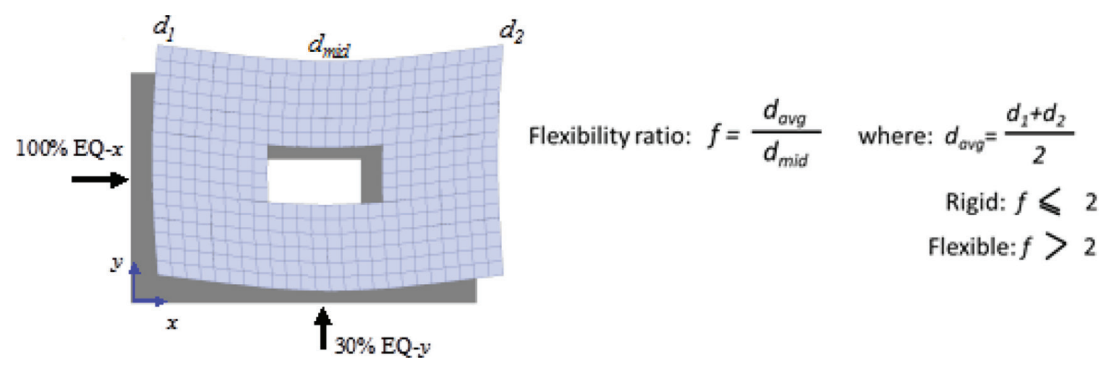

Figure 10: Diaphragm response under combined seismic load and flexibility ratio. 
2.3. The other earthquake loading direction $(30 \%-\mathrm{X}+100 \%-\mathrm{Y})$ that results in critical drifts produced diaphragm flexibilities (for both systems) in the order or 1.1, which is quite rigid. For the six-storey case, no significant difference in the rigidity is obtained between concrete and CLT slab floor diaphragms. Rigid floor assumption is reasonable for floor simple layout and without shear wall core. Work is ongoing to determine other diaphragms responses for the reinforced concrete framework.

Modeling of explicit diaphragm as part of three-dimensional building elements is always advantages. Main modeling consideration is that diaphragms need to be modeled as shell elements, which normally require adequate meshing. This could lead to extensive computer resource allocation when non-linearity (e.g. P-delta, non-linear material response, non-linear time history, etc.) and slab connectors (spring elements) are incorporated in the analysis. For the CLT slab, the connection between the slab and steel frame can be modeled as rigid, provided in the design that the mechanical connectors (e.g. long screws) are designed based on the force demand. Extended modeling work results indicated that there was relatively no significant discrepancy in the structural performances between the floor systems in which their connection systems were modeled using actual connector stiffness and using rigid connectors. This would actually save modeling effort as in the general concrete floor design and analysis.

\section{CONCLUSIONS AND RECOMMENDATIONS}

It can be concluded from this study that significant differences in the structural performances were found between flexible (actual properties) and rigid diaphragm models for multi-storey hybrid building with complex floor layouts and buildings having shear walls. The CLT slab shows larger differences relative to the concrete slab due to significant difference in the lateral stiffness between the CLT-based diaphragm and lateral load resisting elements. The rigid versus flexible assumptions would yield close results in the overall structural response for a case when there is no shear walls. Seismic design code for hybrid timber buildings must be updated to provide provisions for obtaining lateral stiffness ratio between diaphragms and lateral load resisting systems, and to define a certain quantitative value to classify diaphragm as rigid or flexible for the purpose of distributing storey shear.

\section{REFERENCES}

[1] Loss, C., Piazza, M. \& Zandonini, R., Innovative construction system for sustainable buildings. IABSE Conference - Structural Engineering: Providing Solutions to Global Challenges, Sept 23-24, Geneva, Switzerland, p. 8, 2015. https://doi.org/10.2749/222137815818357034

[2] Asiz, A. \& Smith, I., Demands placed on steel frameworks of tall buildings having reinforced concrete or massive wood horizontal slabs. Structural Engineering International, 19(4), pp. 395-403, 2009.

https://doi.org/10.2749/101686609789847000

[3] Asiz, A. \& Smith, I., Connection system of massive timber elements used in horizontal slabs of hybrid tall buildings. ASCE Journal of Structural Engineering, 137(11), 1390-1393, 2011. https://doi.org/10.1061/(ASCE)ST.1943-541X.0000363

[4] Asiz, A. \& Smith, I., Control of building sway and force flows using ultra-lightweight slabs. ASCE Journal of Performance of Constructed Facilities, 28(6), 2014. https://doi.org/10.1061/(ASCE)CF.1943-5509.0000580 
[5] Ju, S.H., \& Lin, M.C., Comparison of building analyses assuming rigid or flexible. ASCE Journal of Structural Engineering, 125, pp. 25-29. https://doi.org/10.1061/(ASCE)0733-9445(1999)125:1(25)

[6] Saffarini, H.S. \& Qudaimat, M.M., In-plane floor deformation in RC structures. ASCE Journal of Structural Engineering (ASCE), 118(11), pp. 3089-3102, 1992. https://doi.org/10.1061/(ASCE)0733-9445(1992)118:11(3089)

[7] Moeini, M. \& Rafezi, B., Investigation into the floor diaphragms flexibility in reinforced concrete structures and code provision. Global Journal of Research in Engineering, 11(1), pp. 25-25, 2011.

[8] Computers and Structures Inc. (CSI)., ETAB - Extended Three Dimensional Analysis of Building Systems, CSI, Berkeley, CA, USA, 2014.

[9] American Institute of Steel Construction (AISC), Steel Construction Manual, 13th edn., AISC, Chicago, IL, 2006.

[10] Institute for Research in Construction (IRC), National Building Code, IRC, National Research Council, Ottawa, Canada, 2010.

[11] International Code Council (ICC), International Building Code, ICC, Washington, DC, USA, 2012.

[12] American Society of Civil Engineering - ASCE (2005). Minimum Design Loads for Buildings and Other Structures, ASCE-7-05, American Society of Civil Engineers, Reston, Virginia. 